\title{
CENTRO DE INVESTIGAÇÃO E DESENVOLVIMENTO EM ETNOBOTÂNICA. MOÇAMBIQUE - ÁFRICA
}

Adelaide Bela Agostinho ${ }^{1}$

\section{INTRODUÇÃO}

A Biodiversidade é parte fundamental da natureza e ela incorpora a fauna e a flora sendo responsável pelo equilíbrio e estabilidade dos ecossistemas. Constitui uma fonte de imenso potencial de uso cultural e econômico. Na realidade ela é a base de vida das populações que a ela recorrem para construção das suas habitações, atividades agrícolas, pecuárias, pesqueiras, florestais, prevenção e cura de doenças e na indústria biotecnológica.

Deste modo, a biodiversidade torna-se muito mais do que a soma de produtos da natureza, pois é a relação do homem com a natureza, é a intervenção das sociedades tradicionais dentro dos habitats naturais em que vivem. As culturas e os saberes tradicionais contribuem para a manutenção da biodiversidade dos ecossistemas. Porque os saberes são o resultado de uma evolução entre as sociedades e seus ambientes naturais, o que permitiu a conservação de um equilíbrio entre ambos. E este conhecimento assim como a prática simbiótica de relação homem-natureza, corre riscos devido à imposição mundial de modelos culturais dominantes.

A biodiversidade aliada aos conhecimentos tradicionais produz benefícios para milhares de pessoas, entretanto os sistemas de patentes e direito de propriedade intelectual colocam em risco esses recursos, de acordo com Vandana Shiva ao afirmar que "Enquanto a biodiversidade e os sistemas de conhecimento indígenas

1 Adelaide Bela Agostinho, Doutorado em Bioquímica Aplicada. Até 2014 foi Diretora Geral do Centro de Investigação e Desenvolvimento em Etnobotânica, Presidente do Conselho Científico de Etnobotânica, Membro do Conselho Nacional de Ciência e Tecnologia e Inovação. De 2001 à 2010 foi Membro da Comissão de Peritos da União Africana, para Área de Plantas Medicinais e Medicina Tradicional e de 2005 a 2013 Membro da Comissão de Peritos da Organização Mundial de Saúde para a Região Africana, para Área de Plantas Medicinais e Medicina Tradicional. 
satisfazem as necessidades de milhões de pessoas, novos sistemas de patentes e de direitos de propriedade intelectual ameaçam apropriar-se destes recursos e processos de conhecimentos vitais do Terceiro Mundo e convertê-los em monopólio vantajoso para as empresas do Norte. As patentes estão, por isso, no centro do novo colonialismo".

Esta constitui uma nova forma de subjugar os povos nativos, apropriando-se de seus conhecimentos, através de mecanismos de propriedade intelectual e consequentemente de patentes aumentando o mercado capitalista, sem benefícios de retorno para os pontos de origem de tais conhecimentos.

A biopirataria, que pode ser entendida como a atividade que envolve o acesso aos recursos genéticos de um determinado país ou aos conhecimentos tradicionais associados a tais recursos genéticos é uma prática de pilhagem da natureza justificada pelo sistema de patente, desfrutado pelas transnacionais farmacêuticas que se beneficiam dos lucros gerados a partir destes conhecimentos sem repartir com os detentores originários dos saberes, e pior sem reposição visto que o meio ambiente sofre seriamente, uma vez que a retirada de matéria-prima vegetal ou animal das florestas não é devidamente controlada e acompanhada por um órgão competente, ocorrendo assim um desequilíbrio no ecossistema local.

Nos Países em Desenvolvimentol a biopirataria não está jurídicamente legislada.

Também o PIB (Produto Interno Bruto) ou a definição de riqueza para um País os recursos vegetais não madeireiros não são levados em consideração. O PIB representa a soma de todas as riquezas produzidas em determinada região ou parcela da sociedade durante um período determinado, avaliando a contribuição produtiva das atividades econômicas. O PIB não tem em conta a contribuição dos recursos vegetais não madeireiros, mas estes contribuem sobremaneira na saúde, alimentação e a qualidade de vida das famílias, garante da geração de rendimentos. Ao considerar a contribuição dos recursos vegetais exportáveis como a madeira, o PIB contabiliza positivamente a destruição organizada do património natural, mas, não o faz em relação às perdas resultantes da destruição, por exemplo, das florestas dos países em desenvolvimento uma atividade que faz avançar o PIB mundial, mas jamais 
contabiliza a perda do patrimônio que resulta dessa atividade, nem as diversas consequências sobre o clima, a biodiversidade e as necessidades das gerações futuras.

\section{CENTRO DE INVESTIGAÇÃO E DESENVOLVIMENTO EM ETNOBOTÂNICA (CIDE)}

Moçambique é um País rico em biodiversidade. Contudo é um dos países mais pobre do mundo. Não tem ainda um regime jurídico que proteja de maneira eficaz os conhecimentos tradicionais. Logo um país vulnerável à espoliação dos seus recursos naturais e dos conhecimentos tradicionais associados a esta garantindo lucros milionários às transnacionais que pilham em especial os recursos vegetais medicinais e patenteiam os medicamentos resultantes sem retorno para o País.

Tendo consciência, do que acontece, e seguindo as recomendações da OMS, no ano de 2004 o governo de Moçambique aprovou a Política Nacional de Medicina Tradicional, em 2008 criou o Centro de Investigação e Desenvolvimento em Etnobotânica como forma garantir aos moçambicanos o acesso seguro e o uso racional de plantas nativas medicinais, alimentares, ornamentais e aromáticas, promovendo o uso sustentável da biodiversidade, o desenvolvimento da cadeia produtiva e da indústria nacional.

Diante do exposto na elaboração da Estratégia da Ciência e Tecnologia de Moçambique (ECTIM), a Etnobotânica foi considerada uma área estratégica transversal que deve de ser desenvolvido com o objectivo de dotar o conhecimento tradicional de valor científico, aplicar os resultados de investigação na produção de bens olhando para a preservação de recursos vegetais e meio ambiente e meIhoria da vida das populações que diariamente recorrem ao uso de recursos vegetais para diferentes fins.

Com efeito, a 30 de Dezembro de 2008, pelo Decreto $\mathrm{nr}$. $60 / 2008$, de 30 de Dezembro foi criado pelo Conselho de Ministros de Moçambique o Centro de Investigação e Desenvolvimento em Etnobotânica - CIDE.

Trata-se de uma instituição pública que além de promover o uso racional das plantas e incentivar à pesquisa científica nesta área de interesse, deve dar subsídios para o empoderamento 
comunitário, com enfoque para aspectos etnobotânicos, taxonômicos, fitoquímicos, toxicológicos, agroecólogicos, alimentares e terapêuticos de plantas, num contexto inter e transdisciplinar. As atividades a serem desenvolvidas por este Centro visam compartiIhar experiências e saberes sobre as plantas, resgatar o conhecimento popular, incentivar a pesquisa científica de cunho acadêmico, divulgar resultados de pesquisa e com bases nestes resultados incentivar a indústria nacional de produtos com base em plantas e formar profissionais nesta área de interesse.

\section{COMPETÊNCIA INSTITUCIONAL}

A investigação em Etnobotânica constitui um meio para promover uma boa gestão dos recursos vegetais e de identificar novos produtos, serviços e usos das plantas (por exemplo, aproveitamento de produtos florestais não madeireiros, isolamento de princípios ativos com interesse farmacológico, identificação de espécies alimentares subaproveitadas) que podem contribuir para o aumento do bem-estar das populações quer a nível local quer global. Neste contexto com a criação do Centro pretende-se promover a valorização e o uso sustentável dos recursos biológicos vegetais não madeireiros, nomeadamente as espécies utilizadas na medicina tradicional, as espécies recoletadas pelas populações e usadas na alimentação, bem como as espécies ornamentais e as aromáticas nativas. Constituem competências do CIDE:

1. Promover e executar a investigação científica na área de etnobotânica;

2. Incentivar e promover o desenvolvimento tecnológico dos resultados da investigação em procedimentos e produtos como meio de valorizar os recursos florísticos do país e apoiar cientificamente o desenvolvimento de pequenas e médias empresas;

3. Promover a formação específica na área da Etnobotânica;

4. Colaborar na divulgação do conhecimento científico através de desenvolvimento de um banco de dados contendo informação sobre a Etnobotânica, apoio à edição de publicações, realização de conferências e outros eventos nacionais e internacionais; 
5. Promoção do registo de produtos resultantes de processos de tecnológicos e de plantas raras e excepcionais e procedimentos para garantir a defesa do Direito de Propriedade Intelectual e de conhecimento tradicional na área de Etnobotânica;

6. Proceder à disseminação de resultados de investigação obtidos bem como a sua aplicação em benefício das comunidades.

\section{VALORES QUE O CIDE DEVE DEFENDER}

A Etnobotânica estuda a interação entre o homem e o mundo vegetal, nas suas diferentes dimensões que vão desde a antropológica, ecológica, botânica, terapêutica, química e toxicológica. Estes estudos são de grande importância para a manutenção da cultura, além de combinar conhecimentos tradicionais e modernos, permitindo uma melhor investigação da flora ainda tão desconhecida e sua conservação e maneio sustentável.

O uso de plantas para fins medicinais, por exemplo, insere-se num contexto social e ecológico que lhe molda, de modo que muitas das peculiaridades do seu emprego só podem ser entendidas se forem levadas em consideração fatores culturais envolvidos e o ambiente físico onde ocorre.

Nas sociedades tradicionais, o principal modo de perpetuação do conhecimento é feito através da transmissão oral. Sobretudo em sociedades rurais ou tradicionais, o conhecimento é transmitido entre gerações e requer contato intenso e prolongado dos membros mais velhos com os mais novos.

A Etnobotânica contribui para o conhecimento da biodiversidade das florestas tropicais, através do registo e resgate dos hábitos e usos de vários povos que possuem estreito vínculo com os recursos de fauna e flora.

Deste modo, o CIDE deve defender os seguintes valores:

I. Defesa do conhecimento tradicional em prol do seu desenvolvimento

II. Valorização do conhecimento tradicional etnobotânico através da Investigação científica e desenvolvimento sustentável;

III. Ética no relacionamento social e científico; 


\section{PRIORIDADES DO CENTRO DE INVESTIGAÇÃO E DESENVOLVIMENTO EM ETNOBOTÂNICA}

O CIDE possui Estatuto Orgânico e batalha agora para que trabalhe com pessoal abalizado e qualificado e que tenha tanto a formação académica adequada ou afim no cerne da investigação em Etnobotânica, quanto na esfera pesquisa de campo e de interacção em plantas medicinais, alimentares e aromáticas entre entidades privadas e públicas, singulares e colectivas, tradicionais e comunitárias com visão clara sobre o uso imediato e futuro das plantas nativas em Moçambique.

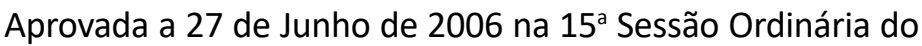
Conselho de Ministros do Governo de Moçambique, a ECTIM (Estratégia de Ciânica, Tecnologia e Inovação de Moçambique) no seu 'Anexo 11: Etnobotânica: Linhas e Programas de Pesquisa, p.132' estabelece como prioridades:

- Criação de uma Base de Informação, para o Conhecimento Etnobotânica;

- Criação dum mecanismo de coordenação para a Investigação da Etnobotânica e seu uso aplicado em programas de desenvolvimento social e económico;

- Pesquisa na caracterização de práticas tradicionais, incluindo aspectos sociais;

- Pesquisa par a valorização do Conhecimento tradicional;

- Pesquisa no uso, produção e comercialização de produtos baseados no Conhecimento local;

- Pesquisa sobre recursos etnobotânicos e a sua utilização em diferentes contextos, via plantas com valor-nutritivo, plantas com valor-medicinal, plantas com propriedades aromáticas para serem utilizadas na produção de insecticidas e de artigos de higiene, para fins cosméticos e na aromaterapia, e plantas para propósitos ornamentais.

Apesar de o CIDE possuir instalações que propiciam o exercício regular, assegurado e atempado de algumas das acções relevantes de atendimento e redimensionamento de protecção e uso das plantas nativas, o presente desafio incide nas áreas de operacionalização do próprio CIDE a seguir mencionadas: 
- Construir novas instalações mais apropriadas para a produção, investigação e forrmação bem como apetrechá-la com equipamento de ponta;

- Apostar na formação de quadros especializados, através da criação de um currículum de etnobotânica a ser introduzido no ensino superior para o nível de mestrado e doutoramento;

- Criar e propôr ao Governo uma Legislação que defenda o Direito de Propriedade de Conhecimento Tradicional.

- Potenciar a dominante da exportação, pelo menos para os países vizinhos de Moçambique de material produzido no Centro;

- Fomentar o Espírito de amor e carinho para com as plantas, inculcando nas crianças a visão da sua importância na vida das populações e do planeta em geral;

- Estabelecer de mecanismos de produção de medicamentos com base em plantas medicinais e que tenham o formato de cremes, pomadas, cartuchos, cápsulas, comprimidos, óleos, bagaço-para-purificação-de-água, xaropes e chás;

- Criar a Tabela de Conversão Alimentar; na qual ficarão expressas as equivalências de nutrientes (calorias, proteínas, vitaminas, aminoácidos e fósforos) entre as plantas comestíveis nativas usadas diariamente pelas populações na sua alimentação;

- Estímular o empresariado nacional com interesse em investir em produtos com base em plantas; e

- Mercantilização de produtos e remédios derivados de plantas medicinais e geração de rendimento financeiro para as famílias mais necessitadas.

\section{DESAFIOS E PERSPECTIVAS}

Apesar de o CIDE possuir instalações que propiciam o exercício regular, assegurado e atempado de algumas das acções relevantes de atendimento e redimensionamento de protecção e uso das plantas nativas, o presente desafio incide em áreas mencionadas a seguir e que são a base para a operacionalização do próprio CIDE: 
- Construir novas instalações mais apropriadas para a produção, investigação e forrmação bem como apetrechá-la com equipamento de ponta;

- Apostar na formação de quadros especializados, através da criação de um currículum de etnobotânica a ser introduzido no ensino superior para o nível de mestrado e doutoramento;

- Criar e Propôr ao Governo uma Legislação que defenda o Direito de Propriedade de Conhecimento tradicional.

- Potenciar a dominante da exportação, pelo menos para os países vizinhos de Moçambique de material produzido no Centro;

- Fomentar o Espírito de amor e carinho para com as plantas, inculcando nas crianças a visão da sua importância na vida das populações e do planeta em geral;

- Estímular o empresariado nacional com interesse em investir em produtos com base em plantas; e

- Mercantilização de produtos e remédios derivados de plantas medicinais e geração de rendimento financeiro para as famílias mais necessitadas.

Assim, tal como as Tecnologias de Informação e Comunicação do mundo contemporâneo e globalizado são instrumentos-de-ponta que consubstanciam de forma transversal a prestação de serviços, incluindo em Moçambique, o CIDE pretende ser um Recinto de eleição, onde académicos, investigadores, pesquisadores, técnicos, admiradores e amantes das plantas medicinais possam trocar ideias, debater conceitos da tradicionalidade, modernidade e contemporaneidade sobre as plantas medicinais, aromáticas e ornamentais e implicações do seu uso regrado para o melhoramento da qualidade de vida das populações moçambicanas.

\section{CONSIDERAÇÕES FINAIS}

O CIDE tem a consciência de que para a concretização de todas as actividades os seus trabalhadores deverão possuir um alto sentido de profissionalismo e de sacrifício, porque socialmente, por ser algo novo, à Etnobotânica ainda não é atribuído valor económico devido, sendo vista com preconceitos que é preciso combater, do 
que com sentimento de necessidade e orgulho de que devemos valorizá-la como Recurso que é cobiçado internacionalmente.

Os conhecimentos tradicionais sempre foram alvo fácil de interesses corporativos coloniais e internacionais, visando sempre à obtenção de riqueza em benefício da atividade expropriante das comunidades detentoras. Neste contexto, são inúmeros os fatos que marcaram a apropriação de tais conhecimentos a nível mundial.

Neste contexto o CIDE tem a missão de resguardar os conhecimentos tradicionais, principalmente porque os processos de biopirataria são evidentes no mundo contemporâneo, desencadeando ações para a criação duma legislação nacional que proteja especialmente o conhecimento tradicional. Essa lei deverá ter em conta inúmeras especificações de como devem ser resguardados e procedidos os meios necessários à efetiva participação dos detentores destes conhecimentos, no que diz respeito aos benefícios econômicos proporcionados pela exploração de matérias-primas e segredos contidos na historia cotidiana da população. Em suma o objetivo da legislação deve ser o de garantir que as patentes e os demais direitos de propriedade intelectual não se oponham aos objetivos da Convenção sobre Diversidade Biológica, ratificada por Moçambique, e os direitos intelectuais coletivos dos detentores de conhecimentos tradicionais sejam respeitados e garantidos. É preciso garantir que a lei proteja eficazmente tais direitos, independentemente da criação ou não de registos e deverão ter sempre uma natureza declaratória, e o acesso e a utilização das informações neles disponíveis deverá sempre respeitar os direitos intelectuais coletivos dos povos tradicionais.

As produções e inovações provenientes de conhecimentos tradicionais têm um valor econômico, e também possuem uma dimensão mitológica simbólica no contexto das populações.

A Convenção sobre Diversidade Biológica (CDB), assinada em 1992, aborda aspectos importantes relacionados com a biodiversidade, tais como: conservação e utilização sustentável, identificação e monitoramento, conservação ex situ e in situ, pesquisa e treinamento, educação e consciencialização pública, minimização de impactos negativos, acesso a recursos genéticos, acesso à tecnologia e transferência, intercâmbio de informações, cooperação técnica e científica, gestão da biotecnologia e repartição de seus benefícios, 
entre outros. O CDB pretende conciliar o desenvolvimento com a conservação e a utilização sustentável da diversidade biológica.

Visto que Moçambique é signatário da CDB, e o CIDE é uma instituição do estado esta instituição deve elaborar ações que venham a dotar o governo e a sociedade de informações necessárias para o estabelecimento de prioridades que conduzam à conservação, à utilização sustentável e à repartição de benefícios da diversidade biológica. Neste contexto, o CIDE em cooperação com o Prof. Dr. Ekbert Hering da Universidade de Aalen, Alemanha desenhou o projeto dos Jardins Etnobotânicos que estão a ser instalados em todos os Distritos do País, como forma de preservar a riqueza vegetal específica de cada região do País.

\section{REFERÊNCIAS}

ASTOS JUNIOR, Luiz Magno Pinto. A Convenção sobre biodiversidade biológica e os instrumentos de controle das atividades ilegais de bioprospecção. Revista de Direito Ambiental. São Paulo, v. 6, n. 23, p. 205-230, jul.set. 2001.

BRAVO, Álvaro Sánchez. Iniciativas de protección penal Del medio ambiente en La Unión Europea. Hiléia: Revista de Direito Ambiental da Amazônia, Manaus, v.4, p.31, jan/jun./2005.

CALIXTO J. B. Twenty-five years of research on medicinal plants in Latin America. A personal view. Journal of Ethnopharmacology. Lausane, v. 100, p. 131-134. 2005.

MASSOCA, Fabiana. S.; AMOROZO Maria. C. de M.; DISTASI, Luis. C. Sociedade de Pesquisa em Vida Selvagem e Educação Ambiental (SPVS. www.aultimaarcadenoe.com www.floramedicinal.com.br www.rc.unesp.br

SANTILLI, Juliana. Biodiversidade e conhecimentos tradicionais associados: novos avanços e impasses na criação de regimes legais de proteção. Revista de Direito Ambiental. São Paulo, v. 8, n. 29, p. 83-102, jan.-mar. 2003.

SHIVA, Vandana. Biopirataria: a pilhagem da natureza e do conhecimento. Trad. Laura Cardellini Barbosa de Oliveira. Rio de Janeiro: Vozes, 2001. 